\title{
REMOÇÃO QUÍMICO-MECÂNICA DA CÁRIE ATRAVÉS DE UM GEL DE PAPAÍNA, UMA ENZIMA DA CASCA DO MAMÃO. RELATO DE CASO
}

\author{
Eliane C Gava Pizi ${ }^{1}$, Camila Beretta Abegão Guimaro ${ }^{2}$, Nathália Lima Merotti ${ }^{2}$ \\ ${ }^{1}$ Docente do Curso de Odontologia da UNOESTE. ${ }^{2}$ Graduadas em Odontologia pela UNOESTE.
}

\section{RESUMO}

Visando diminuir os inconvenientes da tradicional remoção da cárie, foi desenvolvido o método de remoção química e mecânica da cárie através de um gel que amolece a dentina infectada, preservando ao máximo o tecido dentário sadio. Com a finalidade de promover a ampla utilização destes sistemas, inclusive em trabalhos de campo e em saúde pública, é que um novo produto, totalmente nacional, à base de papaína e cloramina foi desenvolvido e denominado Papacárie. O presente relato tem por objetivos descrever a técnica de utilização do Papacárie em paciente infantil demonstrando seu protocolo de utilização. Foi selecionado um paciente de 8 anos de idade, que apresentava lesões de cárie com necessidade de tratamento restaurador. Após a aplicação do gel de papaína aguardou-se de 30 a 40 segundos para, em seguida realizar a curetagem do tecido cariado infectado e a lavagem abundante da cavidade com água. Após o procedimento da curetagem foi então realizada a restauração dos dentes com Compômero. Neste estudo de caso o tecido infectado foi facilmente removido pelo operador e o paciente não relatou dor e nem desconforto durante o tratamento. Mostrando assim que o gel Papacárie é de fácil utilização e muito prático, sendo uma ótima alternativa para remoção de tecido cariado, principalmente em crianças e em pacientes que têm medo do barulho do motor de alta ou baixa rotação. Pode também ser utilizado na técnica atraumática de remoção da cárie (ART), além de conservar ao máximo a estrutura dental sadia.

Palavras-chave: Cárie, papacárie, gel de papaína, remoção química da cárie, carisolv.

\section{CHEMICAL AND MECHANICAL REMOVAL OF CARIES THROUGH A GEL OF PAPAIN, AN ENZYME PEEL PAPAYA}

\begin{abstract}
Seeking to decrease all the inconveniences of the traditional removal of the caries, the method of chemical and mechanical removal of the caries was developed through a gel that soften the infected dentine, preserving to the maximum the healthy dental. With the purpose of promoting the wide use of these systems, besides in field works and in public health, it is that a new product, totally national, to the papain base and cloramine it was developed and denominated Papacarie. The present report has for objectives to describe the technique of use of Papacarie in patient pediatric dentists demonstrating its use protocol. An 8 year-old patient was selected, that presented decay lesions with need of restoring treatment. After the application of the papain gel it was awaited of 30 to 40 seconds for soon after to accomplish the curettage of the fabric infected carious and the abundant wash of the cavity with water. After the procedure of the curettage it was then accomplished the restoration of the teeth with Compomers. In this case study the infected fabric was removed easily by the operator and the patient didn't tell pain and nor discomfort during the treatment. Showing the gel as soon as Papacarie is of easy use and very practical, being a great alternative for removal of carious, mainly in children and in patients that she is afraid of the noise of the discharge motor hight or it lowers rotation.
\end{abstract}

Keywords: Caries, papacárie, papain gel, chemical removal of the caries, carisolv. 


\section{INTRODUÇÃO}

A cárie dentinária é uma infecção bacteriana crônica multifatorial que determina a destruição localizada de tecidos dentários mineralizados. O tratamento tradicional para a remoção da cárie inclui o uso de brocas adaptadas a motores de baixa e/ou alta rotação, de modo a tornar a cavidade pronta para receber o material restaurador. A busca por métodos que simplifiquem a técnica remoção de tecido cariado e que priorizem a conservação desta estrutura levou a estudos constantes por produtos viáveis e de baixo custo, para a remoção químicomecânica do tecido cariado.

$\mathrm{Na}$ dentina cariada podem ser identificadas diferentes camadas histológicas. As duas primeiras camadas caracterizam-se (1) pela presença de tecido necrótico, seguido por (2) zona repleta de bactérias, de fácil remoção e insensível à instrumentação. Estas camadas superficiais mostram-se descalcificadas e com fibras colágenas degradadas. Uma (3) zona de desmineralização aparece como terceira camada, a qual apresenta dentina de consistência mais firme, maior percentual de cálcio do que as camadas anteriores, prolongamentos odontoblásticos, fibras colágenas preservadas e baixa concentração de bactérias. A última camada aparece como (4) dentina esclerosada (SOUZA et al., 2007).

Os métodos utilizados para remover tecido cariado devem ser capazes de distinguir a camada interna da cárie do tecido mais superficial e altamente infectado, em que as fibras de colágeno não podem mais ser remineralizadas. Além disso, esses métodos devem ser confortáveis para o paciente, de fácil utilização, silenciosos, indolores e não devem causar vibração.

As principais desvantagens do tratamento tradicional são: a possibilidade de desgaste abusivo da cavidade e remoção de tecido saudável, que pode levar à exposição da polpa, aquecimento, pressão exagerada sobre a polpa, vibração, ruído, estímulo doloroso e a necessidade de anestesia local, o que provoca aversão em muitos pacientes, especialmente em crianças (CORRÊA et al., 2007a).

O método de remoção químico-mecânico de cárie foi desenvolvido especificamente para superar essas barreiras e preservar o tecido saudável de dentina. Esse método é caracterizado pela utilização de um material que atua sobre o colágeno infectado da lesão, promove o seu amolecimento, não afeta os tecidos saudáveis adjacentes e evita estímulos de dor (ação química). Este método é caracterizado por remoção do tecido cariado amolecido através de escavação suave (ação mecânica), o que torna esta uma técnica eficaz para o tratamento de lesões de cárie aliados ao tratamento restaurador não traumático (CARRILLO et al., 2008).

As primeiras publicações referentes ao sistema de remoção químico-mecânico de tecido cariado foram realizadas na década de 70 , com avaliações do sistema chamado Caridex, produto que foi, inicialmente, introduzido no mercado americano em 1985 (MORROW et al., 2000 apud MATOS \& PORTO, 2007). Todavia, o elevado custo e a dificuldade de manipulação tornaram seu uso pouco viável clinicamente (ERICSON et al., 1999, BEELEY et al., 2000 e MARAGAKIS et al., 2001 apud MIYAGI et al., 2006). Em 1990, a Medi Team lançou no mercado o Carisolv que, apesar de apresentar maior afinidade ao tecido cariado em relação ao Caridex, era difícil de ser removido da dentina sadia circunvizinha (DALE BORNSTEIN, 2000 apud MIYAGI et al., 2006). Essa técnica possui a vantagem de ser frequentemente indolor, indicada para pacientes pediátricos e odontofóbicos, podendo ser utilizada para lesões de cárie radicular, reduzindo a utilização de instrumentos rotatórios (PINHEIRO 
et al., 2004). Sua principal diferença em relação a outros produtos foi o uso de 3 aminoácidos. Apesar da efetividade do Carisolv na remoção da cárie dentária, apresentou algumas desvantagens, tais como o alto custo, que fez sua popularização impossível, tornando a remoção químico-mecânica de cárie um privilégio de poucos. Outro fator que impossibilitou a popularização do seu uso clínico foi a necessidade de importação do produto, o que dificultava o acesso ao mesmo.

Em 2003, um novo material, o Papacárie (Fórmula e Ação, São Paulo, SP, Brasil), foi desenvolvido inicialmente com o propósito de atuar apenas na dentina cariada desorganizada, facilitando a sua remoção por meio de cureta sem corte. Esse produto apresenta-se na forma de gel, composto por papaína, cloramina, azul de toluidina, sais e espessante. Seus principais componentes ativos, a papaína e a cloramina, possuem propriedades bacteriostáticas, bactericidas e anti-inflamatórias. Supõe-se que, por conter substâncias antimicrobianas, o Papacárie poderia auxiliar na redução de microrganismos cariogênicos durante a sua aplicação no tratamento das lesões de cárie (BORTOLETTO et al., 2005).

O Papacárie é um produto nacional, patenteado, registrado e aprovado pela ANVISA. Seu componente principal, a papaína, é uma enzima extraída do látex das folhas e frutos do mamão verde adulto, Carica Papaya, a qual é uma endoproteína à pepsina humana (Candido, 2001 apud SILVA et al., 2004).

Bussadori et al. (2005) salientaram as indicações do gel Papacárie, o qual pode ser utilizado com sucesso em pacientes com necessidades especiais, Odontopediatria, adultos fóbicos, cáries muito próximas à polpa, ou seja, em qualquer tipo de lesão de cárie, sendo uma das suas principais utilizações sua aplicação em saúde pública, devido ao seu baixo custo. Além disso, não há qualquer risco se o gel entrar em contato com tecidos moles bucais, pois o mesmo não é tóxico. O Papacárie alia praticidade, facilidade de utilização, baixo custo e não requer o uso de anestesia local (VENTIN et al., 2003; PEREIRA et al., 2004). Além disso, o potencial antimicrobiano do Papacárie em relação ao Streptococcus mutuans e Lactobacilus é maior do que o do Carisolv (MOTTA et al., 2005).

É claro também que, quando comparados o Carisolv e o Papacárie, as evidências científicas atuais conferem ao Carisolv maior visibilidade internacional em razão das pesquisas já publicadas, ao passo que o Papacárie necessita de um maior número de pesquisas para comprovar sua efetividade prática clínica (AMMARI \& MOLITERNO, 2005). Entretanto, muitos pesquisadores têm se empenhado para que mais comprovações científicas aconteçam (SILVA et al., 2005). Mastrantonio (2007) verificou que tanto o Papacárie quanto o Carisolv são biocompatíveis com o tecido conjuntivo, fato este também verificado por Miyagi et al. (2006).

O presente relato teve por objetivo descrever a técnica de utilização do Papacárie em paciente de odontopediatria, demonstrando seu protocolo de utilização.

\section{RELATO DO CASO}

Foi selecionado um paciente, J.S.S, sexo masculino, 8 anos de idade, estudante de Escola Municipal de Ensino Fundamental da cidade de Presidente Prudente, que apresentava lesões de cárie com necessidade de tratamento restaurador. No exame clínico foi verificada lesão nos dentes canino inferior direito (83), primeiro molar inferior direito (84) e canino superior direito (53) (Figura 1, A e B). 

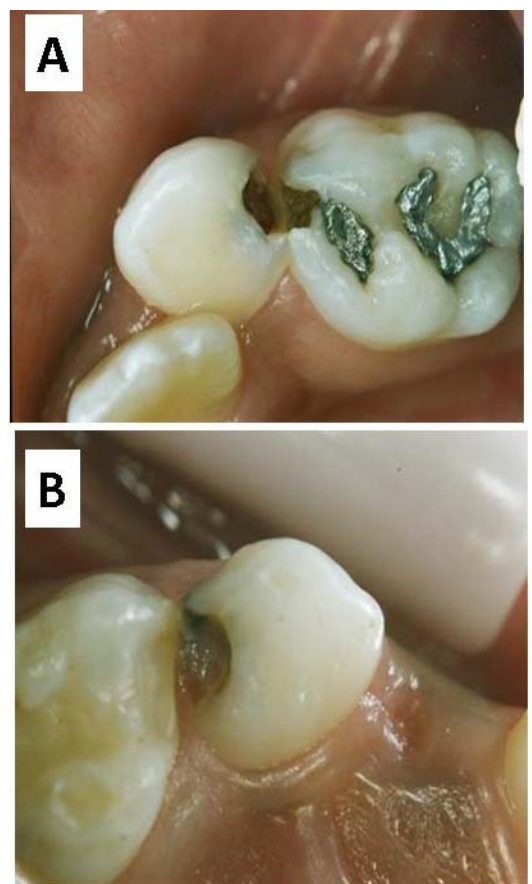

Figura 1. Lesão cárie nos dentes 83, 84 (A) e 53 (B).

Os materiais utilizados para a remoção da dentina infectada pela cárie foram colheres de dentina sem corte e o gel Papacárie. Os passos realizados no paciente foram profilaxia com taça de borracha e Pedra Pomes, isolamento relativo do campo operatório e aplicação do gel papacárie com seringa (Figura 2, A e B).
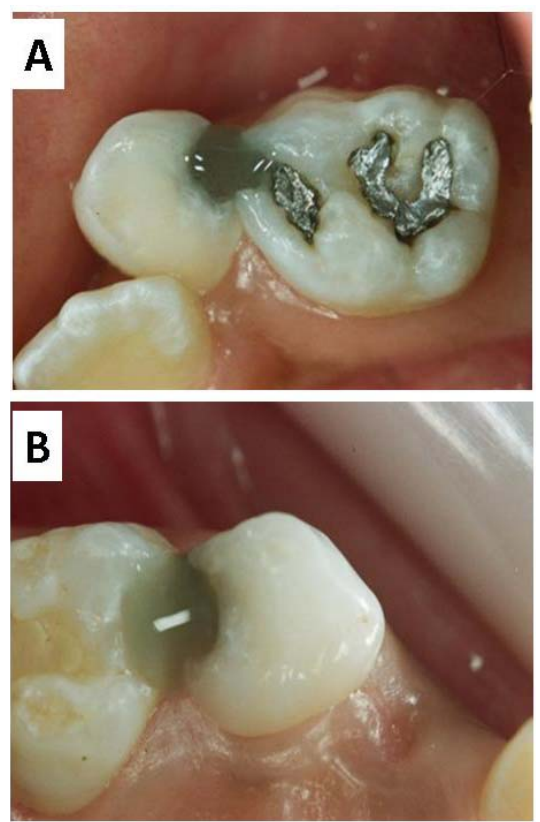

Figura 2. Aplicação do gel Papacárie (A e B).

Aguardou-se de 30 a 40 segundos para, em seguida realizar a curetagem do tecido cariado infectado (Figura 3, A e B). Neste caso optou-se por realizar a reaplicação do gel de Papacárie e, após aguardar de 30 a 40 segundos, curetou-se novamente e realizou-se a lavagem abundante da cavidade com água.

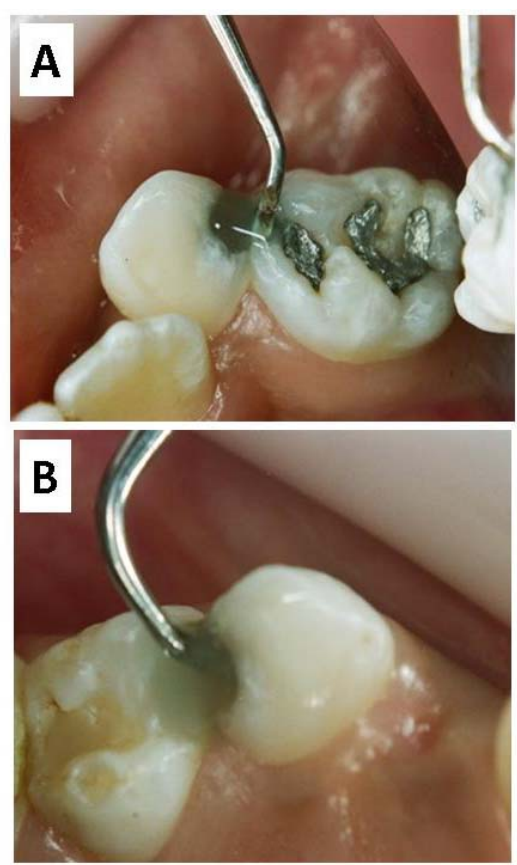

Figura 3. Curetagem da dentina infectada (A e B).

Observa-se na Figura 4A a grande quantidade de tecido dentinário infectado removido com o auxílio da cureta e o aspecto final da cavidade (Figura 4, B e C).

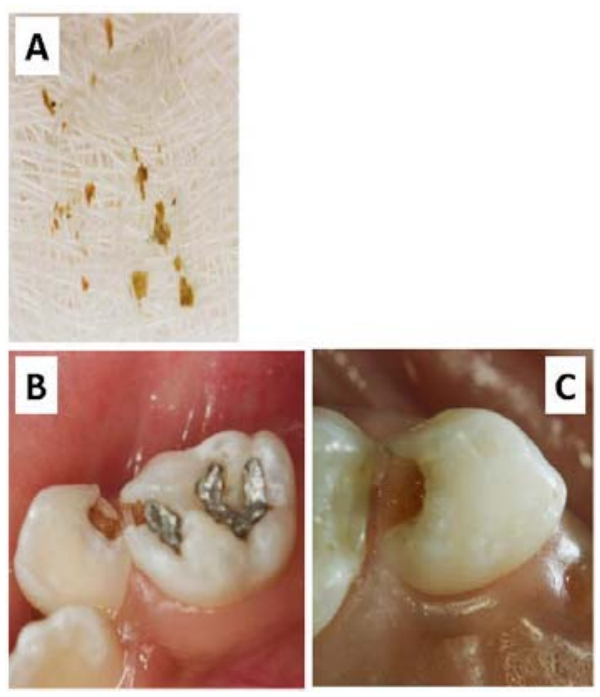

Figura 4. Dentina infectada removida $(A)$ e cavidades após a curetagem (B e C). 
Após o procedimento da curetagem foi então realizada a restauração dos dentes com Compômero (F200, 3M) (Figura 5, A e B).

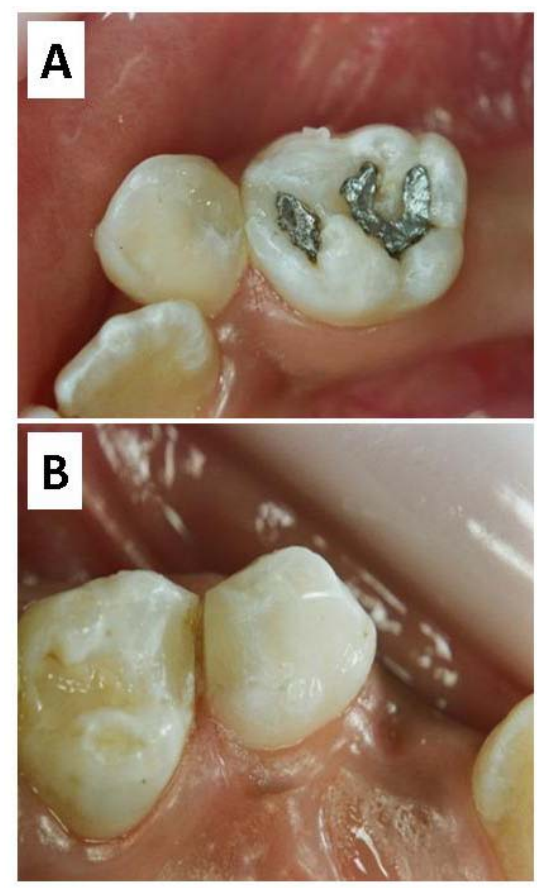

Figura 5. Restauração com Compômero (A e B).

\section{DISCUSSÃO}

Devido à necessidade de uma Odontologia mais conservadora, a evolução das técnicas para remoção do tecido cariado tornouse inevitável. O desenvolvimento da remoção química e mecânica do tecido cariado surgiu com a preocupação cada vez maior de preservar as estruturas dentais sadias (REIS et al., 2003). Dentro da filosofia da Intervenção Mínima, uma das técnicas baseia-se na aplicação de uma solução que facilita apenas a remoção do tecido infectado por meio de instrumentos manuais sem corte, preservando os tecidos dentários sadios, o que inclui a dentina afetada por cárie passível de remineralização (BATISTA, 2006).

O método convencional de remoção de cárie, além de aumentar a possibilidade de sobre extensão da cavidade, desgasta tecido sadio, aquece o dente, exerce pressão e vibração sobre a polpa, estimula a dor e é considerada ruidosa. Diferentemente, a técnica na qual se utiliza o gel pode favorecer ao atendimento mais confortável, devido sua capacidade de reduzir a ansiedade do paciente, pois não se faz necessária à utilização de anestesias e de brocas em alta rotação (CARRILLO et al., 2008). Também não foi utilizado o evidenciador de cárie após a curetagem, justamente por se tratar de uma intervenção menos invasiva e necessidade de preservar maior estrutura dental sadia passível de remineralização. Hoje, já se tem discutido muito o uso dos evidenciadores de cárie, pois evidenciam também estruturas sadias removendo mais profundamente não só a cárie, mas também desnecessariamente a estrutura dental sadia.

A dentina cariada apresenta duas camadas: uma mais externa, denominada dentina infectada, que apresenta tecido irreversivelmente desmineralizado, infectado, que deve ser removida; e uma camada mais interna, chamada dentina afetada, pouco desmineralizada e infectada, que pode ser preservada, pois é passível de remineralização. Assim, no Papacárie, a enzima papaína age quebrando as moléculas de colágeno parcialmente degradada e, a dentina não necrosada, com possibilidade de regeneração, é preservada pelo produto. A cloramina rompe as pontes de hidrogênio intermolecular, facilitando a remoção de tecido cariado (SOUZA et al., 2007).

Em 2004, Pinheiro et al. indicaram a utilização do Carisolv ressaltando suas vantagens, entretanto, as dificuldades em conseguir este material e o alto custo acabaram por inviabilizar a sua popularização.

Como desvantagem relatada do método químico-mecânico, a remoção do tecido é mais lenta, tornando-se necessário gastar maior tempo clínico (CORRÊA et al., 2007b). Entretanto, Motta et al. (2009) relatam ser de 6 minutos o tempo estimado para o tratamento com o Papacárie.

A adesão à dentina não depende somente do sistema adesivo utilizado, mas 
também do substrato dentinário remanescente após a remoção do tecido cariado (CORRÊA et al., 2007b). Tanto o Papacárie quanto o Carisolv formam em dentina uma camada amorfa, semelhante à camada de smear layer e com poucos túbulos dentinários expostos (CORRÊA, 2005). Entretanto, Piva et al. (2008) verificaram que a resistência de união é diminuída quando dentes que fizeram uso de adesivos autocondicionantes são usados após o tratamento com o Papacárie, fato que não aconteceu quando um adesivo não auto-condicionante foi utilizado. Fato este em desacordo com a pesquisa de MELLO et al. (2008).

Importante ressaltar também que um adequado procedimento restaurador é imprescindível já que a remoção do tecido cariado, independente da técnica (convencional ou químico-mecânica) não impede a infiltração marginal na interface dente/restauração (ARAÚJO et al., 2008).

De acordo com Corrêa et al. (2007b) podem ser utilizados diferentes métodos para a remoção do tecido cariado, devendo a escolha se basear na preferência profissional e na melhor adequação a cada caso.

Neste estudo de caso, o tecido infectado foi facilmente removido pelo operador e o paciente não relatou dor e nem desconforto durante o tratamento. Mostrando assim, que o gel Papacárie é de fácil utilização e muito prático, sendo uma ótima alternativa para remoção de tecido cariado, principalmente em crianças e em pacientes que têm medo do barulho do motor de alta ou baixa rotação. Podendo também ser utilizado na técnica atraumática de remoção da cárie (ART), além de conservar ao máximo a estrutura dental sadia.

\section{CONFLITO DE INTERESSE}

Os autores declaram não haver qualquer potencial conflito de interesse que possa interferir na imparcialidade deste trabalho científico.

\section{REFERÊNCIAS}

Ammari MM, Moliterno LFM. Remoção químicomecânica da cárie: evidências atuais. Rev Bras Odontol. 2005;1/2(62):125-7.

Araújo NC, Oliveira APB, Rodrigues VMS, Andrade PMMS. Análise da microinfiltração marginal em restaurações de cimentos ionoméricos após a utilização de Papacárie ${ }^{\circledR}$. Rev Odonto Ciência. 2008;2(23):161-5.

Batista MTV. Odontologia minimamente invasiva. Medcenter. 2006. Disponível em: http://www.odontologia.com.br/artigos. asp?id=678 . Acesso em: 17.03.2009.

Bortoletto CC, Ferrari JCL, Motisuki C, Spolidorio DMP, Santos-Pinto L. Atividade antimicrobiana de um novo biomaterial utilizado na remoção químico-mecânica da cárie. Rev Odontol UNESP. 2005;4(34):199-201.

Bussadori SK, Martins MD, Fernandes KPS, Guedes CC, Motta LJ, Redá SH, Santos EM. Avaliação da biocompatibilidade "in vitro" de um novo material para a remoção química e mecânica de cárie - papacárie. Pesq Bras Odontopediatria Clín Integ. 2005;3(5):253-9.

Carrillo CM, Tanaka MH, Cesar MF, Camargo MAF, Juliano Y, Novo NF. Use of Papain Gel in disabled patients. J Dent Child. 2008;75:222-8.

Corrêa FNP. Avaliação da dentina remanescente após remoção de cárie com instrumento cortante rotatório e métodos químico-mecânicos, utilizando análise de microdureza, fluorescência laser e MEV. Monografia (Graduação). Universidade de São Paulo. Faculdade de Odontologia. 129p. $2005 . \quad$ Disponível em: http://www.teses.usp.br/teses/disponiveis/23/2313 2/tde-06032006-124318/. Acesso em: 17.03.2009.

Corrêa FNP, Rocha RO, Rodrigues Filho LE, Muench A, Rodrigues CRMD. Chemical Versus Conventional Caries Removal Techniques in Primary Teeth: A Microhardness Study. J Clin Pediatr Dent. 2007a;3:189-94

Corrêa FNP, Rodrigues Filho LE, Rodrigues CRMD. Evaluation of Residual Dentin after Conventional and Chemomechanical Caries Removal Using SEM. J Clin Pediatr Dent. 2007b;2(32):115-20. 
Matos CS, Porto RB. Métodos químico-mecânicos de remoção de tecido cariado. UFES Rev Odontol. 2007;9(2):46-50.

Mastrantonio SS. Avaliação da biocompatibilidade de materiais para remoção química da lesão de cárie: análise histológica em tecido conjuntivo de camundongos. (Tese). Universidade Estadual Paulista. Faculdade de Odontologia de Araraquara. 96p. 2007.

Mello HR, Costa KT, Gonzales M, Fraga RC. Influência do uso do Papacárie nas propriedades de sistemas adesivos. Rev Bras Odontol. 2008Rio de Janeiro, v. 65, n. 1,p.8-11,jan./jun..

Miyagi SPH, Mello I, Bussadori SK, Marques MM. Resposta de fibroblastos pulpares humanos em cultura ao gel de papacárie ${ }^{\circledR}$. Rev Odontol Univ Cid São Paulo. 2006;3(18):245-9.

Motta LJ, Martins MD, Porta KP, Bussadori SK. Aesthetic restoration of deciduous anterior teeth

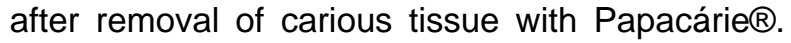
Indian J Dent Res. 2009;1(20):117-20. http://dx.doi.org/10.4103/0970-9290.49060

Motta LJ, Bussadori SK, Guedes CC, Reda SH, Santos EM. Avaliação in vitro do potencial antimicrobiano de dois sistemas para remoção químico mecânica de dentina cariada: CarisolvÖ e Papacárie®. Arq Odontol. 2005;4(41):296-305.

Pereira AS, Silva LR, Motta LJ, Bussadori SK. Remoção químico mecânica de cárie por meio do gel papacárie. Rev RGO. 2004;5(52):385-88.

Pinheiro SL, Aoki CMB, Mendes FM, Bengtson NG, Engston AL. Avaliação Morfológica da dentina após diferentes métodos de remoção do tecido cariado. Rev Assoc Paul Cir Dent. 2004;58(5):363-8.

Piva E, Ogliari FAO, Moraes RR, Cora F, Henn S, Correr-Sobrinho L. Papain-based gel for biochemical caries removal: influence on microtensile bond strength to dentin. Brazil Oral Res. 2008;4(22):364-70. http://dx.doi.org/10.1590/S180683242008000400014

Reis A, Bauer JRO, Loguercio AD. Dureza da dentina após remoção de cárie: avaliação de diferentes métodos / Dentinal hardness after caries removal: evaluation of different methods. RFO UFP. 2003;8(2):56-61.

Silva LR, Murilo JH, Santos EM, Pinto ACG, Bussadori SKalil. Utilización del gel de la papaya para la remoción de la caries: reporte de un caso con seguimiento clínico de un año. Acta Odontol Venez. 2005;2(43).
Silva LR, Motta LJ, Reda SH, Façanha RA-A, Bussadori SK. Papacárie $\AA$ : um novo sistema para a remoção química e mecânica do tecido cariado: relato de caso clínico. Rev Paul Odontol. 2004;6(26):4-8.

Souza RAS, Marsiglio AA, Lopes LG, Pedrosa SF, Costa AM. Análise In Vitro da atividade antimicrobiana do Papacárie sobre Streptococcus mutans. Rev Assoc Paul Cir Dent. 2007;61(5):364-9.

Ventin D, Apfel M, Lange AAR. Remoção químico-mecânica de tecido cariado: Alternativa no tratamento de lesões dentinárias. Rev APCD. 2003;57(2). 